many are strongly against such a practice. Like our expert assessors, they work hard and unpraised for scant reward, yet the quality of the journal depends on them: we owe them a great debt of gratitude.

1 O'Donnell, M, British Medical fournal, 1978, 1, 504.

2 De Bahey, L, The Scientific fournal. St Louis, Mosby, 1966.

3 Woodford, F P, and O'Connor, M, Editing Publishable Manuscripts. Tunbridge Wells, Pitman Medical. In preparation.

\section{Sleep-induced respiratory obstruction and the heart}

Readers of Dickens's Pickwick Papers will be familiar with the fat boy: he was for ever falling asleep, "and snores as he waits at table." In 1965 Gastaut et al described how patients with the Pickwickian syndrome had nocturnal sleep characterised by an endless succession of apnoeic periods, each of which ended with violent snorts and arousal- to such a degree and with such frequency that the sleepiness by day could be understood as a consequence of lack of deep nocturnal sleep. When such patients were given tracheostomies their nocturnal sleep became normal, and their daytime sleepiness vanished, ${ }^{2}$ to reappear if, a year or more later, the tracheostomy was occluded. ${ }^{3 \cdot 5}$

Obesity had been a traditional feature of the syndrome, but Lugaresi et $a l^{6}$ reported similar phenomena in non-obese patients, again relieved by tracheostomy. They suggested that sleep-induced upper-airway obstruction should be considered among the causes of insomnia, ${ }^{7}$ a fact later championed by workers at Stanford. ${ }^{8}$ Upper airway obstruction from adenoids and tonsils was already known to cause pulmonary hypertension and congestive heart failure in children, ${ }^{910}$ and it now became clear that tracheostomy was the only way of arresting or reversing progression to cor pulmonale in adults with the syndrome of sleep-induced apnoea. ${ }^{34}$

Recently the Stanford group have described the cardiovascular accompaniments of the syndrome in 15 patients, ${ }^{11} 12$ eight of whom were treated by tracheostomy. The recurrent apnoeic episodes lasted 10-90 seconds each and occupied over half the total duration of sleep. During each episode the pressure in the pulmonary artery rose, and in most patients there was a progressive rise of both pulmonary and systemic arterial pressure throughout the whole night. In a few patients the airway obstruction disappeared during each period of REM (paradoxical) sleep, and when this happened the hypoxaemia and raised arterial pressure always abated.

Whereas normal sinus rhythm was present during wakefulness, a cyclic pattern of gross sinus arrhythmia appeared with the endless succession of apnoeas during sleep, the heart rate falling below 30 per minute and rising up to 120 every minute or so. Prolonged sinus pauses of as much as six seconds, second degree atrioventricular block, complex ventricular contractions, and limited runs of ventricular tachycardia were also observed. These abnormalities virtually disappeared after tracheostomy, but recurred if it was occluded. Twenty-fourhour monitoring of the electrocardiogram led the Stanford group to propose that the cardiac arrhythmias might account for the sudden deaths to which these patients are prone during sleep. The mechanism of the respiratory obstruction brought about by sleep is not yet clear and probably varies among patients, but oropharyngeal spasm or the falling backwards of the tongue may account for most cases.
The clinical recognition of the syndrome rests on a relative or close companion describing sleep as an endless succession of absent breathing followed by violent snorting, with usually a complaint of severe daytime sleepiness and often obesity. Observation and continuous monitoring of the electrocardiogram, respiration, and sleep throughout the night are the next steps. After diagnosis, the first stage in treatment is the reduction of obesity-before tracheostomy, even though this operation may prove to be vital for some patients.

${ }^{1}$ Gastaut, H, Tassinari, C A, and Duron, B, Revue Neurologique, 1965, 112, 568.

2 Hishikawa, Y, Furuya, E, and Wakamatsu, H, Folia Psychiatrica et Neurologica faponica, 1970, 24, 164

${ }^{3}$ Kuhlo, W, and Doll, E, Bulletin de Physio-pathologie Respiratoire, 1972, $8,1205$.

${ }^{4}$ Coccagna, G, et al, Bulletin de Physio-pathologie Respiratoire, 1972, 8, 1217.

5 Walsh, R E, et al, Annals of Internal Medicine, 1972, 76, 185.

${ }^{6}$ Lugaresi, E, et al, fournal of Neurology, Neurosurgery and Psychiatry, 1973, 36, 15.

Lugaresi, E, Coccagna, G, and Mantovani, M, Bulletin de Physiopathologie Respiratoire, 1972, 8, 1249.

${ }^{8}$ Guilleminault, G, Eldridge, F L, and Dement, W C, Science, 1973, 181, 856.

9 Levy, A M, et al, New England fournal of Medicine, 1967, 277, 506.

10 Ainger, L E, British Heart fournal, 1968, 30, 356.

11 Guilleminault, C, et al, fournal of Neurology, Neurosurgery and Psychiatry, 1977, 40, 718 .

1. Tilkian, A G, et al, American fournal of Medicine, 1977, 93, 348.

\section{Poisoning with alkylmercury compounds}

Isolated instances of human mercury intoxication have been known for centuries, but the use of organic mercury compounds as fungicides has led to large-scale poisoning of whole communities. In the past 20 years there have been thousands of cases and something approaching 1000 deaths. ${ }^{1}$

The first reported widespread epidemic took place in Japan in the 1950s. Methylmercury, a byproduct of the plàstics industry, was discharged into Minamata Bay in effluent and accumulated in high concentrations in the fish. Residents of the bay were poisoned after eating the fish. ${ }^{2}$ One of the first outbreaks associated with mercurial fungicides was in Pakistan in 1961, when over 100 people had chronic mercurial poisoning after eating treated seeds. Of 34 patients admitted to hospital, four died and five were removed while seriously ill by their families. ${ }^{3}$ Nevertheless, the worst outbreaks have been in Iraq, where ethyl mercury $p$-toluene sulphonanilide was introduced as a pesticide in seed dressing by the Ministry of Agriculture in 1955. The farmers were supplied with the treated seeds and warned against eating them. Some farmers thought that washing the seeds with water would rid these of the mercury and then used it for making domestic bread. The first few sporadic cases were seen at the Republican Hospital in Mosul, in the north of Iraq, with neurological manifestations, including unsteadiness, tremor, and loss of vision and hearing. A total of 100 were seen between 1955 and 1959, and of these 14 died from the effect of the poison. ${ }^{4}$

The most catastrophic epidemic ever recorded took place among farmers and their families in Iraq in the winter of 1971-2, when 6530 patients were admitted to hospital. An account of the clinical features and progress of some affected children appears at p 613. Again, exposure to alkylmercury took place when farmers ate home-made bread made from grain treated with a methylmercury fungicide. ${ }^{56}$ The signs of 